\title{
An Amperometric Nitrite Biosensor Based on the Bioelectrocatalysis of Hemoglobin Incorporated in Sol-gel Film
}

\author{
Yixin Sun, ${ }^{a, b}$ Shengfu Wang ${ }^{b, *}$ \\ ${ }^{a}$ School of Sciences, Zhejiang Forestry University, Lin'an 311300. P R China \\ ${ }^{\mathrm{b}}$ Ministry-of-Education Key Laboratory for the Synthesis and Application of Organic Functional Molecules \& College \\ of Chemistry and Chemical Engineering, Hubei University, Wuhan 430062, P. R. China \\ *Corresponding Authors: \\ S. Wang \\ Phone: +86-27-50865309 \\ Fax: +86-27-88663043 \\ E-mail address: wangsf@hubu.edu.cn (S. Wang) \\ Received: 23 February 2009; | Revised: 13 March 2009; | Accepted: 26 March 2009

\begin{abstract}
A highly sensitive, fast and stable biosensor for determination of nitrite was developed using hemoglobin immobilized on a poly (N-isopropylacyamide-co-3- methacryloxypropyltrimethoxysilane) (PNM) modified glass carbon electrodes. The matrix provided a biocompatible microenvironment for retaining the native structure and activity of the entrapped hemoglobin. Nitrite could be reduced by the electrocatalysis of the entrapped hemoglobin without any mediator. The reagentless sensor exhibited a fast response (less than $8 \mathrm{~s}$ ) and sensitivity as high as $0.73 \mu \mathrm{AmM} \mathrm{cm} \mathrm{m}^{-2}$. The linear range for nitrite determination was from 0.11 to $1.88 \mathrm{mM}$ with a detection limit of $2.0 \times 10^{-5} \mathrm{~mol} \mathrm{~L}^{-1}$.
\end{abstract}

Keywords: Hemoglobin; PNM; Bioelectrocatalysis; Biosensor; Nitrite.

\section{Introduction}

Nitrite is one of the well-known inorganic pollutants in environmental, food, industrial and physiological systems. The widespread nitrite pollutant becomes toxic in human body and Animals [1]. So some Communities have established the maximum admissible levels of nitrite in drinking water at $0.1 \mathrm{mg} / \mathrm{L}$, increasing the demand for sufficiently sensitive, accurate and uncomplicated analytical procedures for nitrite.
Spectrophotometric methods for the determination of nitrite have been developed over the past several decades [2-4]. However, these methods required large and expensive instrument and extensive pre-treatment of the sample and thus were limited. Biosensors incorporating proteins or enzymes have also been used for nitrite analysis in real samples with reasonable sensitivity and selectivity. Such as hemoglobin entrapped in carbonized titania nanotubes [5], $\mathrm{Fe}_{3} \mathrm{O}_{4}$ nanoparticles [6], zeolite particles [7], nitrite 
reductase immobilized on Methyl viologen/ Nafion composite film [8], ordered mesoporous titanium oxide matrix [9] and so on. The development of optical nitrite biosensors is of great interest.

PNM is a kind of new sol-gel material [10], which is promising as an immobilization matrix because of its water-solubility, biocompatibility, and good film forming ability at extra-mild conditions. Herein, we studied the direct electron transfer of hemoglobin $(\mathrm{Hb})$ entrapped in PNM films at glassy carbon (GC) electrodes. The immobilized $\mathrm{Hb}$ showed an enhanced electron transfer behavior. We found that nitrite $\left(\mathrm{NO}_{2}{ }^{-}\right)$can be catalytically reduced at the $\mathrm{Hb}-\mathrm{PNM} / \mathrm{GC}$ electrode. The simple process constructs a highperformance nitrite biosensor.

\section{Experimental}

Reagents. Cattle hemoglobin was from Fluka. Sodium nitrite $\left(\mathrm{NaNO}_{2}\right)$ was from Beijing Shuanghuan Chemicals. All other chemicals were reagent grade. All of the chemicals were used as received. All the water used in the experiment was deionized water that was purified twice successively by ion exchange and distillation. Buffers for voltammetry all contained $100 \mathrm{mM}$ $\mathrm{KBr}$. Buffer solution were $25 \mathrm{mM}$ citrate for $\mathrm{pH}$ 3.0-6.0, $25 \mathrm{mM}$ phosphate for $\mathrm{pH} 7.0-8.0$, and 25 $\mathrm{mM}$ borate for $\mathrm{pH}$ 9.0-10.0.

Apparatus. Electrochemical measurements were performed at a CHI660 electrochemistry workstation ( $\mathrm{CH}$ Instruments Co., USA). The electrochemical cell consisted of a three-electrode system where the modified glass carbon electrode $(\mathrm{d}=3 \mathrm{~mm})$ was used as the working electrode, a platinum wire as a counter electrode and a saturated calomel electrode (SCE) as the reference electrode. All measurements were carried out at a room temperature. All experimental solutions were deaerated by bubbling highly pure nitrogen for $15 \mathrm{~min}$, and a nitrogen atmosphere was kept over the solution during measurements.

Electrode modification. Prior to coating, GC electrodes were polished with $0.05 \mu \mathrm{m}$ alumina and sonicated in deionized water three times. They were then treated in 1:1 (v/v) aqueous nitric acid for $10 \mathrm{~min}$, followed by rinsing and sonication in water and methanol successively. A PNM solution $\left(0.1 \mathrm{~g} \mathrm{~mL}^{-1}\right)$ was prepared by dissolving the PNM in a aqueous solution at refrigerator ( 4 ${ }^{\circ} \mathrm{C}$ ) for $30 \mathrm{~min}$. The concentration of the Hb stock solutions, prepared by dissolving $\mathrm{Hb}$ in $0.05 \mathrm{M}$ phosphate buffer solution ( $\mathrm{pH} 7.0$ ), was $10 \mathrm{~g} \mathrm{~L}^{-1}$. A $15 \mu \mathrm{L}$ volume of PNM and $10 \mu \mathrm{L}$ of DMF were mixed with $15 \mu \mathrm{L}$ of the Hb stock solution, and then $20 \mu \mathrm{L}$ of the mixture was pipetted onto the surface of the pretreated GC and spread gently over the entire surface. A small bottle was fit tightly over the electrode so that water evaporated slowly and more uniform films were formed. The films were then dried in air overnight. The PNM film modified GC electrode was prepared in the same way as described above but without $\mathrm{Hb}$.

\section{Results and discussions}

UV-vis spectroscopy of $\mathbf{H b}$ in a PNM film. The locations of the Soret absorption band of iron heme may provide information about the denaturation of heme proteins. When heme proteins were denatured, the Soret band shifted or disappeared [11]. UV-vis spectroscopy was thus here to detect the change of Soret band of $\mathrm{Hb}$ in PNM films cast on the glass slides. In this study, the $\mathrm{Hb}$ concentration and the ratio of $\mathrm{Hb}$ to $\mathrm{PNM}$ and DMF were the same for both UV-vis spectroscopy and electrochemical experiments. Figure 1 show Soret bands of dry films cast from $\mathrm{Hb}$ and $\mathrm{Hb}-\mathrm{PNM}$ and $\mathrm{Hb}-\mathrm{PNM}+\mathrm{DMF}$ solutions at 412, 414, $418 \mathrm{~nm}$ (Figure 1a, b and c), respectively. These suggest that $\mathrm{Hb}$ in dry-PNM films has a secondary structure nearly the same as the native state of $\mathrm{Hb}$ in its dry films alone and no significant denaturation has occurred for $\mathrm{Hb}-\mathrm{PNM}$ films containing DMF.

The Soret band caused by visible absorbance by the Fe (III) heme in protein was sensitive to $\mathrm{pH}$ [12]. It can be seen that the Hb-PNM film absorption spectrum exhibits a strong heme Soret band at nearly $412 \mathrm{~nm}$ in the range of $\mathrm{pH} 5.0$ 9.0, However, when $\mathrm{pH}$ was decreased to below 4.0 , the $412 \mathrm{~nm}$ Soret band absorption shifted and became broader and smaller (Fig 1d), indicative of a great change in heme pocket. These results are in agreement with those of Palaniappan [13] and Liu [14].

(C) 2009 by NWPII. All rights reserved. 


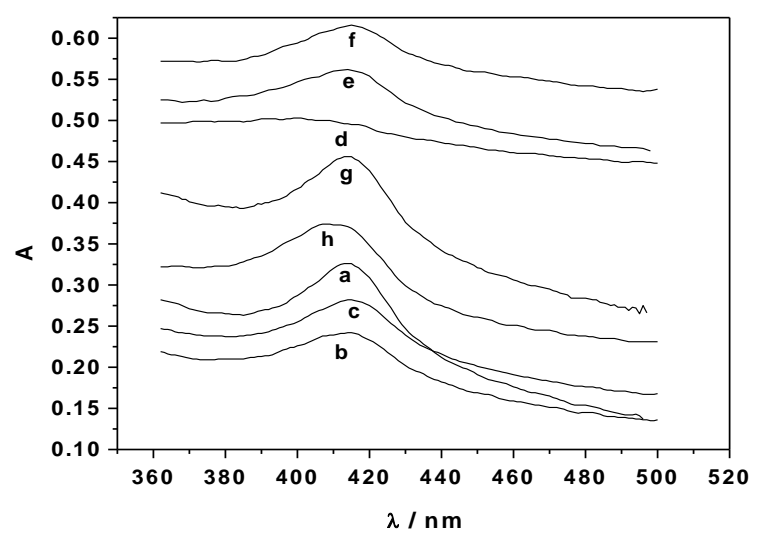

Figure 1. UV-Vis absorption spectra of $\mathrm{Hb}$ and $\mathrm{Hb}-\mathrm{PNM}$ films on glass slides for: (a) dry $\mathrm{Hb}$ film; (b) dry Hb-PNM film; (c) dry Hb-PNM+DMF film and $\mathrm{Hb}-\mathrm{PNM}$ films in different $\mathrm{pH}$ buffer solution: (d) $\mathrm{pH} 3.0$; (e) $\mathrm{pH} 4.5$; (f) $\mathrm{pH} 5.5$; (g) $\mathrm{pH}$ 7.0; (h) $\mathrm{pH} 9.0$

\section{Direct electrochemistry of $\mathrm{Hb}$ in a PNM}

film. Figure 2A shows the cyclic voltammograms of $\mathrm{Hb}$-PNM modified GC electrode in $\mathrm{pH} 7.0$ buffer solution. It gives a pair of very stable and well-defined peaks. The peaks are located at the potentials characteristic of the heme $\mathrm{Fe}^{\mathrm{III}} / \mathrm{Fe}^{\mathrm{II}}$ redox couples of the proteins [15]. No redox peaks are observed at PNM modified GC electrode in the same potential range (Figure2A (a)).

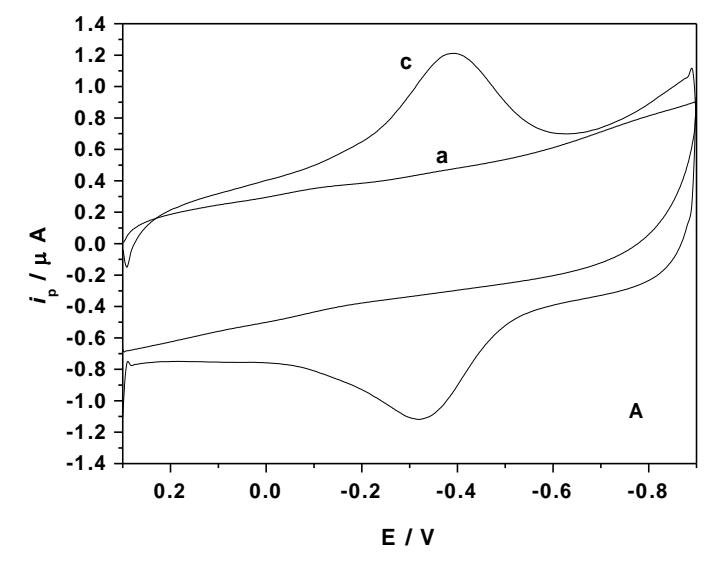

Figure. 2A: Cyclic voltammograms of PNM /GC (a) and $\mathrm{Hb}-\mathrm{PNM} / \mathrm{GC}(\mathrm{c})$ in $\mathrm{pH} 7.0$ buffer solution at $0.2 \mathrm{~V} / \mathrm{s}$ scan rates.

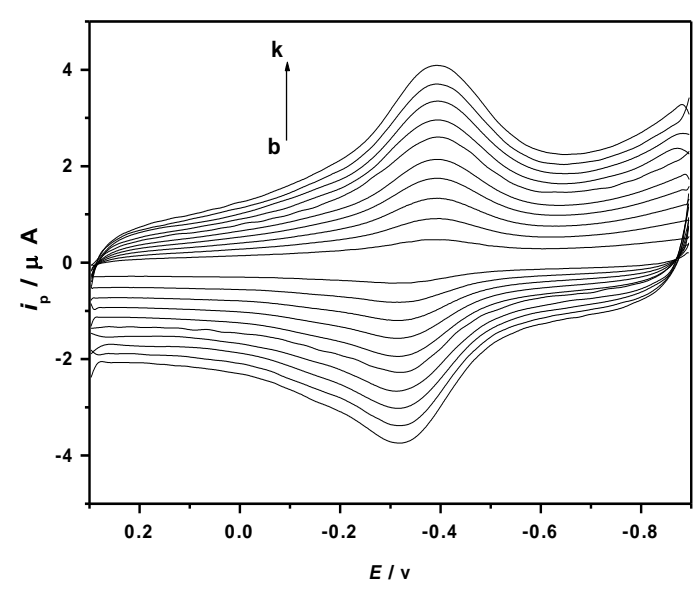

Figure 2B: Cyclic voltammograms of $\mathrm{Hb}$ PNM/GC(c) in $\mathrm{pH} 7.0$ buffer solution at varying scan rates $(\mathrm{b} \rightarrow \mathrm{k}): 0.1,0.2,0.3,0.4,0.5,0.6,0.7$, $0.8,0.9,1 \mathrm{~V} / \mathrm{s}$.

These results coincide well with previous studies on $\mathrm{Hb}$ immobilized in other films $[16,17]$. The anodic and cathodic peak potentials of $\mathrm{Hb}$ $\mathrm{PNM} / \mathrm{GC}$ electrode at the scan rate $0.2 \mathrm{Vs}^{-1}$ are $0.318 \mathrm{~V}$ and $-0.392 \mathrm{~V}$ (Figure 2A(c)) respectively. The difference between the anodic peak potential $\left(E_{\mathrm{pa}}\right)$ and the cathodic peak potential $\left(E_{\mathrm{pc}}\right)$ ) of $74 \mathrm{mV}$ show that the redox process is a typical quasi-reversible electrochemical process involving an active substance attached to the electrode. The anodic and cathodic peak currents for immobilized $\mathrm{Hb}$ are found to increase linearly with scan rates from 0.1 to $1 \mathrm{~V} \mathrm{~s}^{-}$

(Figure 2B), as expected for thin-layer electrochemical behavior [18]. The surface coverage $(\Gamma)$ of $2.07 \times 10^{-11} \mathrm{~mol} \mathrm{~cm}{ }^{-2}$ is estimated according to Laviron's equation [19]

$$
\mathrm{I}_{\mathrm{p}}=\mathrm{n}^{2} \mathrm{~F}^{2} \mathrm{~A} \Gamma \mathrm{v} / 4 \mathrm{RT} \text {. }
$$

This value is below the total amount of $\mathrm{Hb}$ deposited on the electrode surface and suggests that only those proteins in the inner layer of the films close to the electrode and with a suitable orientation can exchange electrons with the electrode.

Average formal potentials $\left(E^{0^{\prime}}=-0.343 \mathrm{~V}\right)$, apparent coverage $\left(\Gamma=1.56 \times 10^{-11} \mathrm{~mol} \mathrm{~cm} \mathrm{~cm}^{-2}\right)$, electron transfer coefficient $(\alpha=0.50)$, and apparent heterogeneous electron transfer rate constants $\left(\mathrm{k}_{\mathrm{s}}=16\right)$ were also estimated by nonlinear regression analysis of square wave voltammetry 
(SWV) forward and reverse curves (Figure 3) [20].

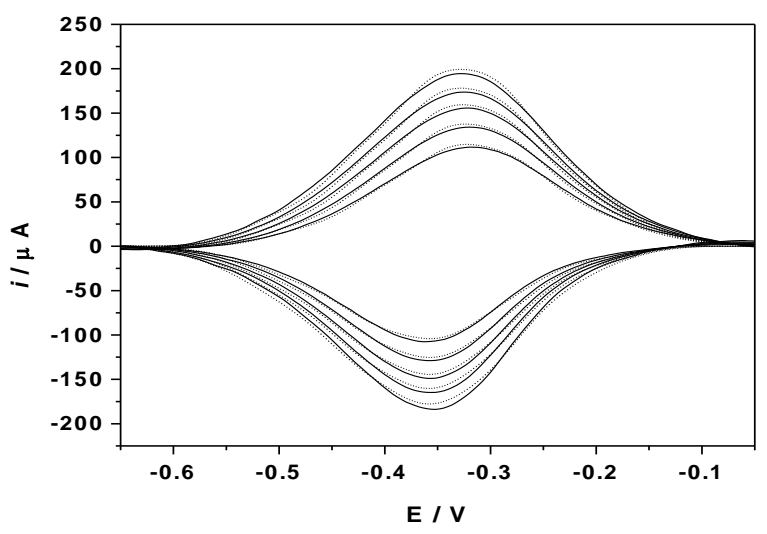

Figure 3. Square wave forward and reverse current voltammograms for Hb-PNM films in $\mathrm{pH}$ 7.0 buffer solution at different frequencies. The solid lines represent the experimental SWV from which background has been subtracted. Points are the best fit by nonlinear regression onto the 5- $E^{0^{\prime}}$ dispersion model. SWV conditions: pulse height $60 \mathrm{mV}$ and frequencies (Hz): (a) 132, (b) 152, (c) 172, (d) 185.

Influence of pH on direct electrochemistry of $\mathbf{H b}$. An increase of $\mathrm{pH}$ of the solution leads to a negative shift in potential for both cathodic and anodic $\mathrm{CV}$ peaks for Hb-PNM film. As shown in Figure 4A, stable and well-defined CVs can be always obtained in the range of $\mathrm{pH} 3.0 \sim 10.0$. The standard electrode potential $\left(E^{0^{\prime}}\right)$ for $\mathrm{Hb}$ in a PNM film shifts to negative with increasing $\mathrm{pH}, E^{0^{\prime}}$ has a linear relationship with linear regression equation of $E^{0^{\prime}}=0.0784-0.0402 \mathrm{pH}(\mathrm{R}=0.9970)$ for $\mathrm{Hb}$ (Figure 4B), indicating the electron transfer of $\mathrm{Fe}^{\mathrm{III}} / \mathrm{Fe}^{\mathrm{II}}$ redox couple company with the transfer of proton. All changes in $\mathrm{CV}$ peak potentials and currents with $\mathrm{pH}$ are reversible.

Electrocatalytic reduction of $\mathrm{NO}_{2}^{-}$on the Hb-PNM/GC electrodes. Figure 5 shows the cyclic voltammograms of Hb-PNM/GC electrodes in $\mathrm{pH} 7.0$ buffer solution. A new reduction peak appears at about $-0.82 \mathrm{~V}$ while the $\mathrm{Hb} \mathrm{Fe}^{\mathrm{III}} / \mathrm{Fe}^{\mathrm{II}}$ peak pair is nearly intact. However, direct reduction of $\mathrm{NO}_{2}{ }^{-}$at blank film electrodes is not observed (Figure 5a), indicating that $\mathrm{Hb}$ entrapped in PNM film catalyze the reduction of $\mathrm{NO}_{2}{ }^{-}$.

\section{A:}

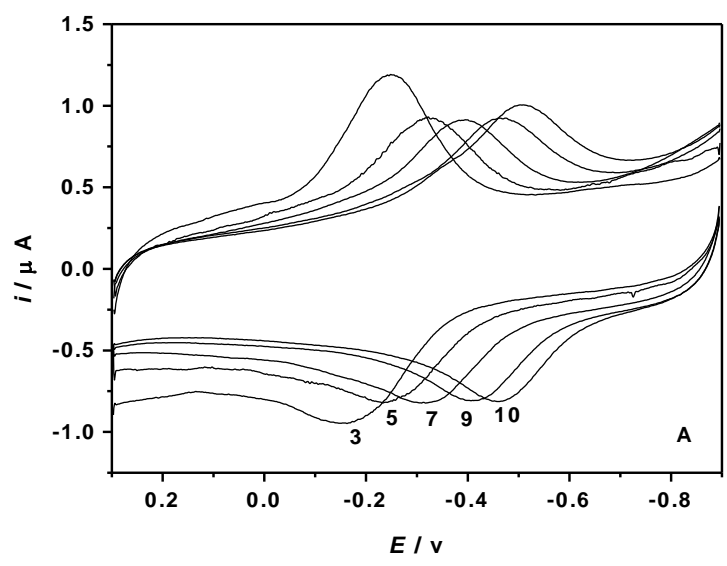

B:

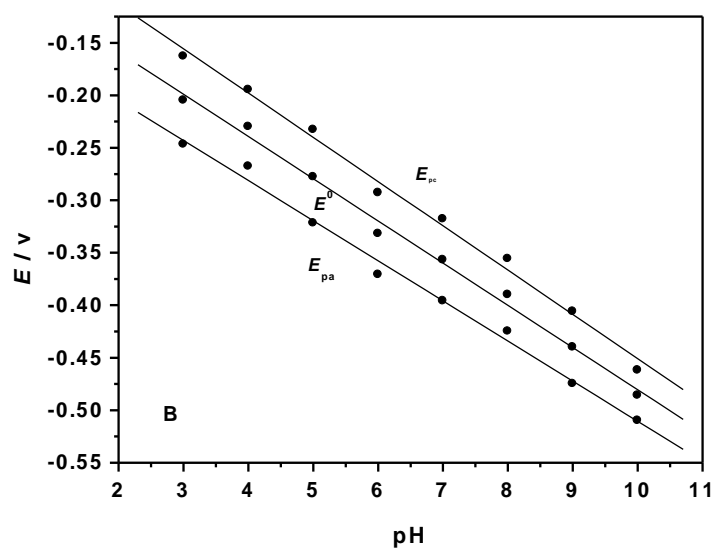

Figure 4. A: Cyclic voltammograms of Hb-PNM /GC in $0.1 \mathrm{M}$ buffer solution at different $\mathrm{pHs}$. Scan rate: $0.2 \mathrm{~V} \mathrm{~s}^{-1}$. B: Plots of $E$ vs. $\mathrm{pH}$.

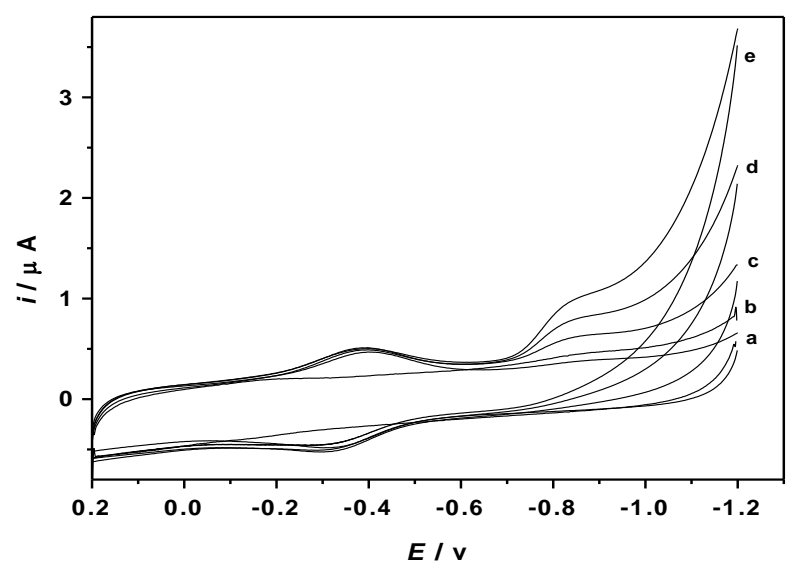

Figure 5. Cyclic voltammograms at $0.1 \mathrm{Vs}^{-1}$ in $\mathrm{pH}$ 7.0 buffer solution: (a) PNM modified GC in 
buffer solution containing $6.68 \times 10^{-4} \mathrm{molL}^{-1}$ $\mathrm{NaNO}_{2}$; (b) Hb- PNM films modified GC in buffer solution without $\mathrm{NaNO}_{2}$; (c-e) Hb-PNM films modified GC electrode in buffer solution containing $0.167,0.668,1.67 \mathrm{mM}$.

Figure 6 shows the amperometric response of the $\mathrm{Hb}-\mathrm{PM} / \mathrm{GC}$ electrode with successive of $\mathrm{NO}_{2}{ }^{-}$ to $\mathrm{pH} 7.0$ buffer solution at an applied potential of - $0.82 \mathrm{~V}$. Upon addition of an aliquot of $\mathrm{NaNO}_{2}$ to the buffer solution, the reduction current of $\mathrm{NO}_{2}{ }^{-}$ increases steeply to reach a stable value. The sensor can achieve a steady state current within 8 $\mathrm{s}$; such a short response time further proves that the PNM is a promising material for the biosensor fabrication. With an increase of $\mathrm{NO}_{2}{ }^{-}$ concentration, the amperometric response increases. Inset in Figure 6 shows the calibration curve of the $\mathrm{Hb}-\mathrm{PNM} / \mathrm{GC}$ electrode to $\mathrm{NO}_{2}^{-}$. The linear response range of the sensor to $\mathrm{NO}_{2}{ }^{-}$ concentration is from 0.11 to $1.88 \mathrm{mM}$ with a correlation coefficient of 0.9987 ( $n=17)$. The detection limit is $2.0 \times 10^{-5} \mathrm{~mol} \mathrm{~L}^{-1}$ at a signal to noise ratio of 3 , which was much lower than that reported for the detection limit of $0.1 \mathrm{mM} \mathrm{NO}_{2}{ }^{-}$ [8], and the sensitivity of the biosensor to $\mathrm{NO}_{2}^{-}$ can be calculated to be $0.73 \mu \mathrm{AmM} \mathrm{cm} \mathrm{m}^{-2}$.

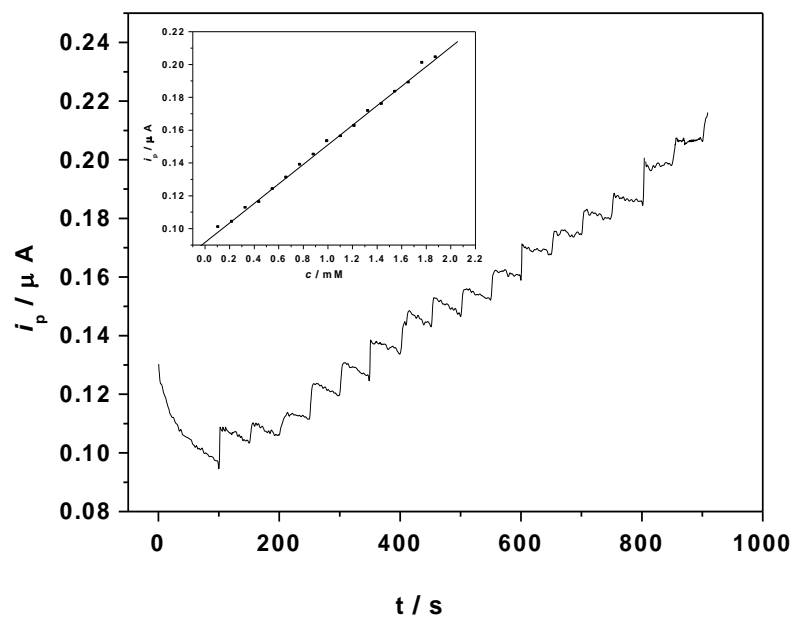

Figure 6. Typical current-time response curve of the sensor upon successive additions of $10 \mu \mathrm{L}$ every time $0.133 \mathrm{~mol} \mathrm{~L}^{-1} \mathrm{NO}_{2}^{-}$to $12.00 \mathrm{~mL} \mathrm{pH} 7.0$ buffer solution at $-0.82 \mathrm{~V}$. Inset: plot of catalytic current vs. $\mathrm{NO}_{2}{ }^{-}$concentration.
Effect of temperature on the $\mathrm{NO}_{2}^{-}$ biosensors. Figure 7 shows the effect of temperature on the sensitivity of the same biosensor. Like the majority of enzymes or proteins, the activity of $\mathrm{Hb}$ is related to temperature, With temperature increasing from 15 to $60{ }^{\circ} \mathrm{C}$, the amperometric responses and the electrocatalytic activities of the immobilized $\mathrm{Hb}$ to $\mathrm{NO}_{2}{ }^{-}$increase. The $\mathrm{Hb}$ has activity even at $60{ }^{\circ} \mathrm{C}$. It is evident that the immobilized $\mathrm{Hb}$ has good thermal stability because of the unchangeability of microenvironment and its native structure upon temperature change. These results indicate that the sensors can handle a wide range of temperature.

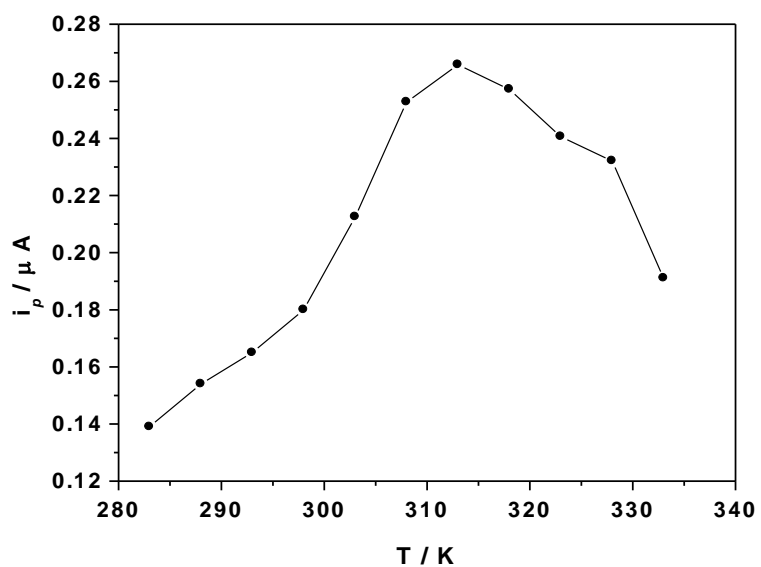

Figure 7. Effect of temperature on the response of the $5.0 \times 10^{-4} \mathrm{~mol} \mathrm{~L}^{-1} \mathrm{NO}_{2}^{-}$biosensor.

Stability and Repeatability of the $\mathrm{Hb}$ PNM/GC modified electrode. Long-term storage stability is one of the key factors of a biosensor performance. The measurement repeatability of the $\mathrm{Hb}-\mathrm{PNM} / \mathrm{GC}$ electrode was examined at a concentration of $5.0 \times 10^{-4} \mathrm{~mol} \mathrm{~L}^{-1} \mathrm{NO}_{2}{ }^{-}$with the same modified electrode and the relative standard deviation (RSD) was $4.3 \%$ for nine successive assays. The fabrication of 4 electrodes, made independently, showed an acceptable reproducibility with a RSD of $4.6 \%$ for the current determined at a $\mathrm{NO}_{2}{ }^{-}$concentration of 5.0 $\times 10^{-4} \mathrm{~mol} \mathrm{~L}^{-1}$, the $\mathrm{Hb}-\mathrm{PNM} / \mathrm{GC}$ electrode were stored in $50 \mathrm{mM} \mathrm{pH} 7.0$ buffer solution at $4{ }^{\circ} \mathrm{C}$, the biosensor showed googd stability over 1 month. Thus, PNM were very efficient in retaining the electrocatalytic activity of $\mathrm{Hb}$ and preventing 
it from leaking out of the sensor. This good stability is mainly attributed to the biocompatible of PNM and the mild immobilization process of HRP. The processes of electrode modification avoid the shortcomings caused by acidic catalyst or calcinations step needed in traditional sol-gel process and maintain their biological activity to a large extent.

\section{Conclusions}

A novel and simple biosensor have been successfully developed. $\mathrm{Hb}$ is immobilized on the PNM film and shows a good direct electrochemistry. The immobilized $\mathrm{Hb}$ displays a high affinity and high response sensitivity to nitrite without mediator. The sensor shows a good reproducibility and stability. PNM provides an efficient strategy and a new promising platform for the study of electron transfer of proteins and the development of biosensors.

\section{Acknowledgements}

The authors wish to thank Prof. J.F. Rusling and Prof. D.W. Pang for providing the software for nonlinear regression analysis of SWV data. This work was supported by the Natural Science Foundation of Zhejiang province, Education Department (No.20060679).

\section{References}

[1] Moorcroft M.J., Davis J., Compton R.G. Detection and determination of nitrate and nitrite: a review. Talanta 2001, 54: 785-803.

[2] Abbas M.N., Mostafa G.A. Determination of traces of nitrite and nitrate in water by solid phase spectrophotometry. Anal. Chim. Acta 2000, 410: 185-192.

[3] Ferree M.A., Shannon R.D. Evaluation of a second derivative UV/visible spectroscopy technique for nitrate and total nitrogen analysis of wastewater samples. Water Res. 2001, 35: 327-332.

[4] Connolly D. Paull B. Rapid determination of nitrate and nitrite in drinking water samples using ion-interaction liquid chromatography. Anal. Chim. Acta 2001,441:53-62.
[5] Guo C.X, Hu F.P, Li C.M et al. Direct electrochemistry of hemoglobin on carbonized titania nanotubes and its application in a sensitive reagentless hydrogen peroxide biosensor, Biosen \& Bioelectron, 2008, 24:819-824.

[6] Cao D.F., Hu N.F. Direct electron transfer between hemoglobin and pyrolytic graphite electrodes enhanced by $\mathrm{Fe}_{3} \mathrm{O}_{4}$ nanoparticles in their layer-by-layer self-assembly films.Biophys.Chem. 2006, 121:209-217.

[7] Xie Y., Liu H.Y., Hu N.F. Layer-by-layer films of hemoglobin or myoglobin assembled with zeolite particles: Electrochemistry and electrocatalysis. Bioelectrochem. 2006, 71: 614.

[8] Wang X.J., Dzyadevych S.V, Chovelon J.M et al. Development of a conductometric nitrate biosensor based on Methyl viologen/Nafion composite film, Electrochem. Coтmu. 2006, 8: 201-205.

[9] Jia N.Q, Wen Y.L, Yang G.F et al. Direct electrochemistry and enzymatic activity of hemoglobin immobilized in ordered mesoporous titanium oxide matrix, Electrochem. Commu. 2008, 10,774-777.

[10] Zhang J. T., Huang S.W., Zhuo R. X. A novel sol-gel strategy to prepare temperaturesensitive hydrogel for encapsulation of protein.Colloid Polym Sci. 2005, 284: 209213.

[11] George P. Hanania G.I.H. Spectrophotometric study of ionizations in methemoglobin. $J$. Biochem. 1953, 55: 236-243.

[12] Brunori M., Giacometti G. M. Antonini E. et al. Denaturation of Aplysia myoglobin. Equilibrium study. J. Mol. Biol. 1972, 63: 139-152.

[13] Palaniappan V., Bocian D.F. Biochem. Acidinduced transformations of myoglobin. Characterization of a new equilibrium hemepocket intermediate.1994, 33: 14264-14274.

[14] Liu H H., Tian Z.Q., Pang D.W. et al. Direct electrochemistry and electro- catalysis of heme-proteins entrapped in agarose hydrogel films.Biosen \& Bioelectron. 2004, 20:294-304.

[15] Zhang Z., Chouchane S., Magliozzo R.S., Rusling J.F. Direct Voltammetry and Catalysis with Mycobacterium tuberculosis Catalase- 
Peroxidase, Peroxidases, and Catalase in Lipid Films.Anal. Chem. 2002, 74:163-170.

[16] Lu Q., Hu S.S. Studies on direct electron transfer and biocatalytic properties of hemoglobin in polytetrafluoroethylene film, Chem. Phys. Lett. 2006, 424: 167-171.

[17] Qi H.L., Zhang C.X., Li X.R. Amperometric third-generation hydrogen peroxide biosensor incorporating multiwall carbon nanotubes and hemoglobin.Sens.\& Actuators B. 2006, 114: 364-370.

[18] Bard A.J., Faulkner L.R. Electrochemical Methods. Wiley, New York 1980 pp. 54-55.
[19] Laviron E. The use of linear potential sweep voltammetry and of a.c. voltammetry for the study of the surface electrochemical reaction of strongly adsorbed systems and of redox modified electrodes. J. Electroanal. Chem. 1979, 100:263-270.

[20] Nassar A.E.F., Zhang Z., Hu N. Rusling J.F., Kumosinski T.F. Proton-Coupled Electron Transfer from Electrodes to Myoglobin in Ordered Biomembrane-like Films. J. Phys. Chem. B 1997, 101:2224-2231. 